\title{
Nutritional encephalomalacia in the chick: an exposure of the vulnerable period for cerebellar development and the possible need for both $\omega 6$ - and $\omega 3$-fatty acids
}

\author{
BY P. BUDOWSKI*, M. J. LEIGHFIELD AND M. A. CRAWFORD† \\ Nuffield Laboratories of Comparative Medicine, Institute of Zoology, \\ Regent's Park, London NWI 4RY
}

(Received 9 October 1986 - Accepted 17 July 1987)

\begin{abstract}
1. Cockerels (1-d-old) received over a period of 4 weeks, a balanced diet containing either safflower oil (diet $\mathbf{S}$ ) or linseed oil (diet L) as a source of polyunsaturated fatty acids (PUFA). Body-weight, and weights of cerebrum and cerebellum increased at similar rates in the two dietary groups. The total fatty acids (FA) of the cerebellum differed from the cerebral FA by their higher PUFA and oleic acid contents and their lower stearic acid level. During the 3rd week of life there was a spurt in accretion of PUFA in the cerebellum, but not in the cerebrum. At the end of the experimental period phosphatidylethanolamine was present at twice the concentration in the cerebellum, compared with the cerebrum.

2. Diets $S$ and $L$ resulted in extensive mutual replacement of $\omega 6-$ and $\omega 3-\mathrm{FA}$ in brain, without any significant change in the total PUFA. Brain oleic acid concentration was higher in the diet- $\mathrm{L}$ group than in the diet- $\mathrm{S}$ group, but saturated FA were not affected by the dietary treatments.

3. These results may be relevant to basic brain biology and to chick nutritional encephalomalacia (NE). This disease, which specifically affects the cerebellum and is readily induced by diets supplying linoleic acid but deficient in vitamin $\mathrm{E}$, usually reaches its highest incidence during the $3 \mathrm{rd}$ week of life and may thus be related to the cerebellar PUFA spurt that occurs at that time. The fact that NE was induced by linoleic acid, while $\alpha-$ linolenic acid exerted a protective action, points to an overproduction of arachidonic-derived eicosanoids as a factor in the etiology of the cerebellar lesion and possibly a structural change due to a loss of docosahexaenoic acid and gain of arachidonic acid in the chicks given diet $\mathbf{S}$.
\end{abstract}

The fatty acid (FA) composition of tissue lipids has long been known to be influenced by the amount and type of polyunsaturated FA (PUFA) supplied by the diet. Compared with liver, brain is resistant to such influences as evidenced by the weak effect of a low-fat diet on rat brain FA composition, even after two generations (Sinclair \& Crawford, 1973). Rat brain is also notoriously difficult to deplete of its $\omega 3$-FA when the diet supplies sufficient linoleic acid (LA) but very low amounts of $\alpha$-linolenic acid (LnA) (Tinoco et al. 1978).

Unlike neonatal mammals, newly hatched birds are exposed from the 1st day to dietary influences which would be expected to affect tissue FA composition. The brain of the young chick is subject to rapid changes in FA composition induced by dietary PUFA, as shown for whole brain by Century et al. (1963) and for cerebellum by Horwitt et al. (1959), Marco et al. (1961) and Budowski et al. (1980). The growing chick is also uniquely susceptible to nutritional encephalomalacia (NE), a classical syndrome of vitamin E deficiency (Pappenheimer \& Goettsch, 1931) in which a severe haemorrhagic lesion develops in the cerebellum associated with extensive oedema. A dietary supply of LA or arachidonic acid (AA) is necessary for the successful experimental induction of the lesion (Dam et al. 1958; Century et al. 1959; Machlin \& Gordon, 1960; Dam \& Sondergaard, 1962). By contrast, LnA protects against the cerebellar lesion (Dam et al. 1958; Century \& Horwitt, 1959; Budowski et al. 1980). However, this effect has received little attention, as interest was focused mainly on LA as a causative factor in the induction of NE.

* Present address: Department of Animal Science, Faculty of Agriculture, The Hebrew University of Jerusalem, Rehovot 76-100, Israel.

$\dagger$ For reprints. 
LnA is converted to a family of higher PUFA and used for building cell membranes in parallel with the products of LA. There is evidence that LnA is an essential fatty acid for fish (Sinnhuber et al. 1972) and rhesus monkeys (Neuringer et al. 1986). We have previously drawn attention to the possibility that eicosanoids are involved in NE and in the protective effect of linseed oil which is due to the presence of LnA (Budowski et al. 1980). The profound effect exerted by dietary PUFA on brain FA composition in the growing chick raises the question of how such changes bear on the incidence of NE. A related point, also investigated in the present study, is why it is the cerebellum and not the cerebrum which is the target in NE.

\section{MATERIALS AND METHODS}

\section{Chicks}

Cockerels (1-d-old Rhode Island Red $\times$ Light Sussex) received the experimental diets ad lib. Several chicks from the two experimental groups were killed by decapitation at the time intervals indicated, cerebral hemispheres (subsequently referred to as 'cerebrum') and cerebellums were removed immediately, weighed and kept frozen at $-18^{\circ}$ under nitrogen.

\section{Diets}

The composition of the diets was as follows $(\mathrm{g} / \mathrm{kg}$ ): oil (see Table 1) 80.0, defatted soyabean meal $550 \cdot 0$, glucose monohydrate $289 \cdot 3$, cellulose 30.0 , mineral mixture $40 \cdot 0$, vitamin mixture $5 \cdot 0$, choline chloride $1 \cdot 3$, DL-methionine $1 \cdot 6$, Terramycin (Pfizer, Sandwich, Kent) $1 \cdot 8$, olive oil containing 2,6-di-tertiary butyl-4-methylphenol $(50 \mathrm{mg} / \mathrm{g} ; \mathrm{BHT}) 1 \cdot 0$. The compositions of the mineral and vitamin mixtures were described previously (Budowski et al. 1979). The experimental oils were either edible safflower oil (diet S) or linseed oil, BP 1963 (diet L) and had the composition detailed in Table 1.

\section{Analytical procedures}

The cerebrum or cerebellum was placed in $15-\mathrm{ml}$ test tubes fitted with Teflon-lined screw caps. Heptadecanoic acid $(0.5 \mathrm{ml}$ of an ethanolic solution containing $2 \mathrm{mg} / \mathrm{ml})$ was added as an internal standard followed by $2.5 \mathrm{ml}$ ethanolic potassium hydroxide. This solution was freshly prepared each day by mixing 8 vol. ethanol containing $100 \mathrm{mg}$ BHT/1 with 2 vol. aqueous potassium hydroxide $(600 \mathrm{~g} / 1)$. The tubes were flushed with $\mathrm{N}_{2}$, capped and heated to $70^{\circ}$ for $1 \mathrm{~h}$. After cooling, $3 \mathrm{ml}$ saline (50 g sodium chloride $/ 1$ ) were added and the unsaponifiables removed by extracting three times with 3-ml portions of petroleum spirit $\left(60-80^{\circ} ; \mathrm{BDH}\right.$, Poole, Dorset). The alkaline solution was acidified with $5 \mathrm{M}-$ hydrochloric acid to about $\mathrm{pH} 4$ and the FA were extracted with two 3 -ml portions of petroleum spirit. The petroleum spirit extract of FA was dried by passing through a column of anhydrous sodium sulphate. Methylation was carried out by heating the FA with $3 \mathrm{ml}$ sulphuric acid $(50 \mathrm{ml} / 1)$ in methanol at $70^{\circ}$ for $1 \mathrm{~h}$. After addition of $3 \mathrm{ml}$ saline, the methyl esters were extracted by shaking once with $3 \mathrm{ml}$ petroleum spirit, concentrated to $100 \mu \mathrm{l}$ and analysed by gas-liquid chromatography (GLC). The instrument was a Pye Unicam gas-liquid chromatograph (series 204) fitted with a flame ionization detector. The glass column ( $1.5 \mathrm{~m}$ long, $4 \mathrm{~mm}$ internal diameter) was packed with $10 \%$ PEGA on Chromosorb W 100-120 and was held at $190^{\circ}$. Dry oxygen-free $\mathrm{N}_{2}$ served as a carrier gas. Peaks were identified by comparison with authentic standards and by equivalent chainlength. Areas were computed by electronic integration, and all compositional values are reported as area percentage. Absolute amounts of total FA were calculated from the sum of the peak areas in relation to the area of the 17:0 FA peak.

FA analysis of total brain lipids after saponification of tissue and removal of cholesterol, 
Table 1. Fatty acid (FA) profiles (weight $\%$ of total $F A$ ) of diet oils

\begin{tabular}{ccc}
\hline \hline FA & $\begin{array}{c}\text { Safflower } \\
\text { oil }\end{array}$ & Linseed oil \\
\hline $16: 0$ & $6 \cdot 6$ & $5 \cdot 2$ \\
$18: 0$ & $2 \cdot 3$ & $3 \cdot 0$ \\
$18: 1 \omega 9$ & $15 \cdot 9$ & $15 \cdot 5$ \\
$18: 2 \omega 6$ & $72 \cdot 7$ & $15 \cdot 9$ \\
$18: 3 \omega 3$ & $0 \cdot 4$ & $58 \cdot 2$ \\
Others & $2 \cdot 0$ & $2 \cdot 2$ \\
\hline
\end{tabular}

as described here, makes possible the simultaneous processing of many samples with minimum exposure and appears to be a satisfactory technique, to judge from the low standard deviations.

For analysis of individual lipid fractions, cerebrums and cerebellums were homogenized in $15 \mathrm{ml}$ chloroform-methanol $(2: 1, \mathrm{v} / \mathrm{v})$ containing $100 \mathrm{mg}$ BHT/l. The extract was filtered through sintered-glass, evaporated to dryness under $\mathrm{N}_{2}$ and taken up in $5 \mathrm{ml}$ of the same solvent.

Thin-layer chromatography was carried out on high-performance silica gel plates, as described by Vitiello \& Zanetta (1978), with the addition of BHT (100 mg/l) to the developing solvent and using 0.5 and $1.5 \mathrm{ml}$ of cerebral and cerebellar extracts respectively. The lipid areas were visualized by spraying the plates with $2^{\prime}, 7^{\prime}$-dichlorofluorescein $(1 \mathrm{~g} / \mathrm{l})$ in methanol $(950 \mathrm{ml} / 1)$ and viewing under U.V. light. The lipid fractions were scraped into methylation tubes, heptadecanoic acid was added in amounts roughly similar to the total amount of FA in that fraction, and transmethylation and GLC were performed under the same conditions as for total FA. The amounts of lipid fractions, expressed as FA, were calculated from the sum of the peak areas in relation to the 17:0 FA area. The four lipid fractions separated and analysed were ethanolamine, serine and choline phosphoglycerides (EPG, SPG and CPG respectively), and sphingomyelin (SPH). They accounted for roughly half the total tissue FA, the rest being presumably contributed by gangliosides and cerebrosides.

Student's $t$ test was used for assessing the significance of differences.

RESULTS

The body-weights of the chicks at 4 weeks averaged $345 \mathrm{~g}$, without significant differences between the dietary groups $(P>0.05)$. The growth of cerebrum and cerebellum, and the accretion of total FA, are shown in Fig. 1. The curves reveal a short spurt in cerebral growth between days 7 and 11, and an increased rate of FA accretion in the cerebellum between days 11 and 21. Neither brain growth nor FA accretion were significantly affected by the dietary treatments $(P>0 \cdot 05)$.

Unlike the total FA content of brain, the PUFA composition of the brain was strongly influenced by the type of dietary PUFA supplied, as illustrated in Fig. 2. The diet S treatment led to an increase in $\omega 6$-FA and a decrease in $\omega 3$-FA, while the opposite effect was achieved with diet L. Total PUFA levels, however, differed only slightly in the two dietary groups, with a tendency toward lower values with diet L. Fig. 2 also shows that the pattern of PUFA changes over the experimental period was different for the cerebrum and the cerebellum: while the content of total PUFA and of $\omega 6$ - and $\omega 3-F A$ in the cerebrum changed smoothly, there were abrupt changes in the cerebellum. This was particularly 


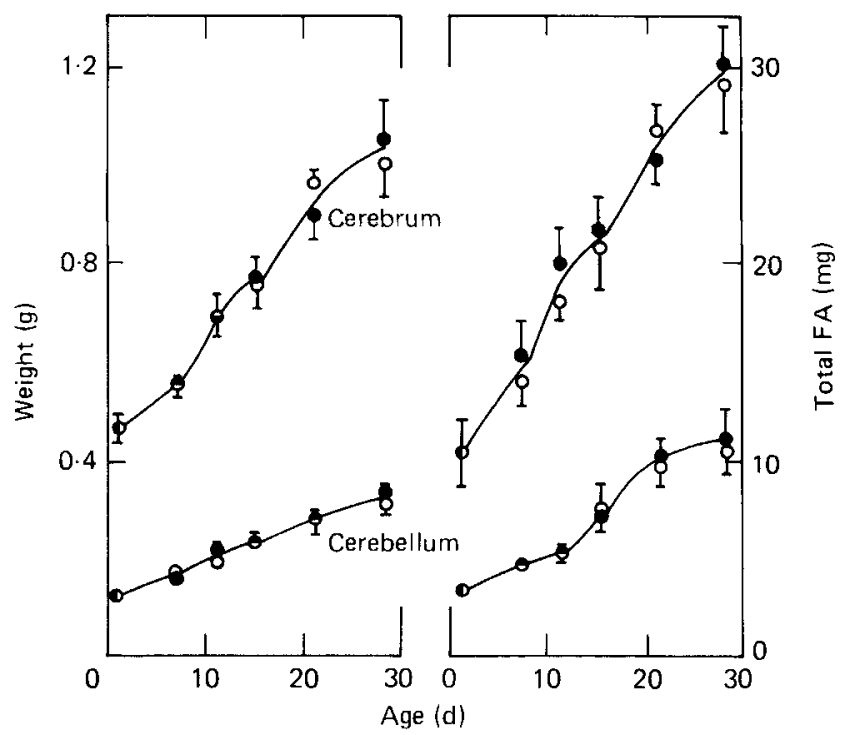

Fig. 1. Brain growth and fatty acid (FA) accretion in chicks receiving safflower oil ( $)$ or linseed oil (O). Each point represents the mean of six chicks, and standard deviations are shown, represented by vertical bars, where they do not fall within the circles. Single lines have been drawn through the two sets of values, as the treatment effects were not significantly different $(P>0.05)$.

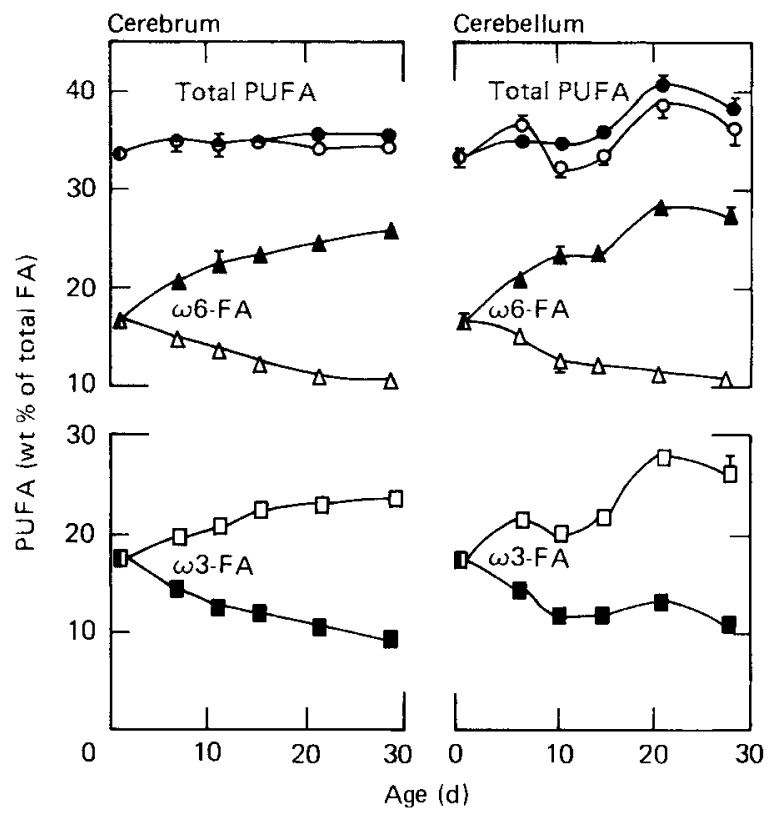

Fig. 2. Changes in polyunsaturated fatty acid (PUFA) content of total fatty acids (FA) in cerebrum and cerebellum of chicks receiving safflower oil $(\boldsymbol{O}, \Delta, \mathbf{D})$ or linseed oil $(O, \Delta, \square) .(\boldsymbol{O}, \bigcirc)$, Total PUFA; $(\mathbf{\Delta}, \triangle), \omega 6-F A ;(\mathbf{\square}, \square),(\omega 3-\mathrm{FA}$. Each point represents the mean of six chicks, and standard deviations are shown, represented by vertical bars, where they do not fall within the symbols. Differences between treatment effects were significant $(P<0.05)$ for total PUFA values in cerebrum on days 21 and 28 , and in cerebellum on days 11,15 and 21 ; and highly significant $(P<0.001)$ for $1,6-$ and $\omega 3$-FA in both parts of the brain at all times after the start of the experiment. 
Table 2. Fatty acid $(F A)$ profiles (weight $\%$ of total $F A$ ) of cerebrum and cerebellum of 28-d-old chicks receiving safflower oil or linseed oil in their diet

(Mean values and standard deviations for six chicks)

\begin{tabular}{|c|c|c|c|c|c|c|c|c|}
\hline \multirow[b]{3}{*}{ FA } & \multicolumn{4}{|c|}{ Cerebrum } & \multicolumn{4}{|c|}{ Cerebellum } \\
\hline & \multicolumn{2}{|c|}{ Safflower } & \multicolumn{2}{|c|}{ Linseed } & \multicolumn{2}{|c|}{ Safflower } & \multicolumn{2}{|c|}{ Linseed } \\
\hline & Mean & SD & Mean & SD & Mean & SD & Mean & SD \\
\hline $14: 0$ & $0 \cdot 36^{\mathrm{a}}$ & 0.06 & $0 \cdot 39^{3}$ & 0.07 & $0.28^{b}$ & 0.06 & $0.28^{b}$ & 0.02 \\
\hline $16: 0$ & $25 \cdot 32^{\mathrm{a}}$ & 0.76 & $24 \cdot 59^{\mathrm{a}, \mathrm{b}}$ & 1.00 & $23.52^{\mathrm{b}}$ & 0.54 & $23 \cdot 64^{\mathrm{b}}$ & 0.36 \\
\hline $16: 1$ & $1 \cdot 18$ & 0.50 & 1.60 & 0.65 & $1 \cdot 31$ & $0 \cdot 31$ & $1 \cdot 54$ & 0.23 \\
\hline $18: 0$ & $19 \cdot 77^{8}$ & 0.38 & $19 \cdot 35^{\mathrm{a}}$ & $0 \cdot 23$ & $14 \cdot 20^{\mathrm{b}}$ & 0.73 & $13 \cdot 77^{\mathrm{b}}$ & 0.99 \\
\hline $18: 1 \omega 9$ & $12 \cdot 56^{\mathrm{a}}$ & 0.45 & $14.71^{b}$ & $0 \cdot 34$ & $16 \cdot 20^{\circ}$ & 0.88 & $19 \cdot 68^{d}$ & 0.69 \\
\hline $18: 2 \omega 6$ & $2 \cdot 34^{a}$ & $0 \cdot 29$ & $1.73^{b}$ & $0 \cdot 29$ & $4 \cdot 04^{\mathrm{C}}$ & $0 \cdot 74$ & $2 \cdot 16^{\mathrm{a}}$ & $0 \cdot 26$ \\
\hline $18: 3 \omega 3$ & ND & & $0 \cdot 83^{a}$ & $0 \cdot 18$ & ND & & $1 \cdot 39^{b}$ & 0.22 \\
\hline $20: 0$ & $0 \cdot 10$ & 0.02 & 0.06 & $0 \cdot 10$ & ND & & ND & \\
\hline $20: 1$ & $0.31^{a}$ & $0 \cdot 10$ & $0 \cdot 33^{a}$ & 0.09 & $0.47^{b}$ & 0.07 & 0.57 & 0.05 \\
\hline $20: 3 \omega 6$ & $0 \cdot 40^{\mathrm{a}}$ & 0.08 & $0 \cdot 44^{\mathrm{a}}$ & 0.02 & $1 \cdot 02^{b}$ & 0.22 & $0.80^{\mathrm{b}}$ & 0.08 \\
\hline $20: 4 \omega 6$ & $12 \cdot 08^{\mathrm{a}}$ & $0 \cdot 40$ & $6.65^{b}$ & $0 \cdot 26$ & $12 \cdot 57^{\mathrm{a}}$ & 1.07 & $5 \cdot 58^{\mathrm{b}}$ & 0.29 \\
\hline $20: 5 \omega 3 \dagger$ & ND & & $1.85^{\mathrm{a}}$ & $0 \cdot 11$ & ND & & $2 \cdot 14^{b}$ & $0 \cdot 17$ \\
\hline $22: 406$ & $4 \cdot 38^{\mathrm{a}}$ & 0.15 & $1 \cdot 13^{8}$ & 0.08 & $4.89^{\circ}$ & 0.23 & $1 \cdot 11^{\mathrm{c}}$ & 0.05 \\
\hline $22: 5 \omega 6 \dagger$ & $6 \cdot 31^{\mathrm{a}}$ & 0.48 & $0.32^{\mathrm{b}}$ & 0.07 & $4 \cdot 58^{\circ}$ & 0.25 & $0 \cdot 44^{\mathrm{d}}$ & 0.06 \\
\hline $22: 5 \omega 3 \dagger$ & $0.58^{\mathrm{a}}$ & 0.25 & $3.08^{\mathrm{b}}$ & $0 \cdot 30$ & $1 \cdot 14^{\mathrm{c}}$ & $0 \cdot 14$ & $4 \cdot 92^{\mathrm{d}}$ & 0.29 \\
\hline $22: 6+13$ & $8.92^{\mathrm{a}}$ & 0.53 & $17.96^{\mathrm{b}}$ & 0.66 & $9 \cdot 59^{\mathrm{a}}$ & 0.73 & $18 \cdot 09^{b}$ & 0.99 \\
\hline Others & $5 \cdot 13^{a, b}$ & 1.07 & $4.99^{a, b}$ & 1.33 & $6 \cdot 18^{a}$ & 1.50 & $3.84^{\mathrm{b}}$ & 0.96 \\
\hline SFA & $45 \cdot 55^{\mathrm{a}}$ & 1.28 & $44 \cdot 39^{a}$ & 1.03 & $37 \cdot 70^{\mathrm{b}}$ & 0.66 & $37 \cdot 70^{\mathrm{b}}$ & 0.67 \\
\hline MUFA & $14 \cdot 07^{a}$ & 0.54 & $16 \cdot 64^{\mathrm{D}}$ & 0.42 & $17 \cdot 96^{\mathrm{c}}$ & 0.77 & $21 \cdot 79^{\mathrm{d}}$ & $0 \cdot 70$ \\
\hline PUFA & $35 \cdot 01^{\mathrm{a}}$ & 0.71 & $33.99^{\circ}$ & 0.71 & $37.83^{c}$ & 1.05 & $36 \cdot 07^{\mathrm{a}, \mathrm{c}}$ & 1.73 \\
\hline$\omega 6$-PUFA & $25 \cdot 51^{\mathrm{a}}$ & 0.32 & $10 \cdot 26^{\mathrm{b}}$ & 0.39 & $27 \cdot 10^{\mathrm{c}}$ & 0.81 & $10 \cdot 10^{\mathrm{b}}$ & 0.46 \\
\hline$\omega 3$-PUFA & $9 \cdot 50^{\mathrm{a}}$ & 0.74 & $23 \cdot 72^{\mathrm{b}}$ & 0.71 & $10 \cdot 73^{c}$ & 0.85 & $25.96^{\mathrm{d}}$ & 1.59 \\
\hline$\omega 3: \omega 6$ & $0 \cdot 40^{\mathrm{a}}$ & 0.04 & $2 \cdot 31^{\mathrm{b}}$ & 0.13 & $0 \cdot 40^{\mathrm{a}}$ & 0.03 & $2 \cdot 57^{\mathrm{c}}$ & 0.18 \\
\hline
\end{tabular}

ND, not detected; SFA, saturated FA; MUFA, monounsaturated FA; PUFA, polyunsaturated FA. a, b, c,d Mean values within rows with unlike superscript letters were signficantly different $(P<0 \cdot 05)$.

$\dagger 20: 5 \omega 3,22: 5 \omega 6$ and $22: 5 \omega 3$ contain traces of $22: 1,24: 0$ and $24: 1$ respectively.

evident for the total PUFA content in both dietary groups and for the $\omega 3$-PUFA with diet $\mathrm{L}$, where maximum values were observed on days 7 and 21 .

Detailed findings on the FA composition of total lipids at 4 weeks are presented in Table 2. Total PUFA and monounsaturated FA values were significantly greater, and therefore saturated FA levels were considerably lower, in the cerebellum than in the cerebrum. These differences were evident in both dietary groups. Among the major FA, the differences were particularly striking for stearic and oleic acids, with a reversal in the relative proportions of these FA between the two parts of the brain.

Table 2 also demonstrates the effect of the dietary oils on the FA composition. The marked dietary influence on brain PUFA, already illustrated in Fig. 2 for $\omega 6-$ and $\omega 3$-FA, was also found for nearly all individual PUFA. In addition, the level of oleic acid in both cerebrum and cerebellum was significantly higher with diet $\mathrm{L}$ than with diet $\mathrm{S}$. Although there was a tendency toward a similar treatment effect in the case of the minor monoenes 16:1 and 20:1, the differences achieved statistical significance only for $20: 1$ in the cerebellum.

The concentrations of some lipid fractions in brain at 4 weeks are given in Table 3 . The level of EPG in the cerebellum was twice that in the cerebrum, but the concentrations of the other lipids were not significantly different. 
Table 3. Concentrations ( $m$ g fatty acids/g brain tissue) of some lipids in cerebrum and cerebellum on day 28

(Mean values and standard deviations for five chicks, two receiving the safflower oil diet and three receiving the linseed oil diet*)

\begin{tabular}{|c|c|c|c|c|c|}
\hline \multirow[b]{2}{*}{ Lipid } & \multicolumn{2}{|c|}{ Cerebrum } & \multicolumn{2}{|c|}{ Cerebellum } & \multirow{2}{*}{$\begin{array}{c}\text { Statistical } \\
\text { significance } \\
\text { (Student's } \\
t \text { test) }\end{array}$} \\
\hline & Mean & SD & Mean & SD & \\
\hline EPG & 3.60 & $0 \cdot 12$ & 6.90 & 0.23 & $P<0.001$ \\
\hline SPG & 3.56 & $0 \cdot 30$ & $3 \cdot 39$ & $0 \cdot 70$ & NS \\
\hline $\mathrm{CPG}$ & $4 \cdot 42$ & 0.72 & 5.46 & 0.85 & NS \\
\hline SPH & 0.83 & 0.07 & 0.82 & 0.16 & NS \\
\hline
\end{tabular}

* The lipid concentrations were the same in the two dietary groups. EPG, SPG, CPG, ethanolamine, serine and choline phosphoglycerides respectively; SPH, sphingomyelin; NS, not significant $(P>0.05)$.

Table 4. Fatty acid (FA) profiles (weight \% of total $F A$ ) of ethanolamine, serine and choline phosphoglycerides (EPG, SPG and CPG respectively) and of sphingomyelin (SPH) in cerebrum and cerebellum of 28-d-old chicks receiving the linseed-oil diet

(Mean values for three chicks)

\begin{tabular}{|c|c|c|c|c|c|c|c|c|}
\hline \multirow[b]{2}{*}{ FA } & \multicolumn{4}{|c|}{ Cerebrum } & \multicolumn{4}{|c|}{ Cerebellum } \\
\hline & $\mathrm{EPG}$ & $\mathrm{SPG}$ & $\mathrm{CPG}$ & SPH & $\mathrm{EPG}$ & SPG & $\mathrm{CPG}$ & SPH \\
\hline $14: 0$ & 0.5 & 0.4 & $0-9$ & 0.5 & $0 \cdot 1^{*}$ & 0.7 & $0.4^{*}$ & 0.5 \\
\hline $15: 0$ & $\operatorname{tr}$ & 0.1 & $0 \cdot 3$ & 0.4 & $\operatorname{tr}$ & $\mathrm{tr}$ & $0 \cdot 1^{* *}$ & 0.4 \\
\hline 16DMA & $4 \cdot 2$ & $\operatorname{tr}$ & $\operatorname{tr}$ & $\operatorname{tr}$ & $2 \cdot 8$ & $\mathrm{tr}$ & $\operatorname{tr}$ & $\operatorname{tr}$ \\
\hline $16: 0$ & $7 \cdot 1$ & $38 \cdot 1$ & $65 \cdot 1$ & $19 \cdot 5$ & $7 \cdot 2$ & $27 \cdot 7^{*}$ & $54 \cdot 9^{*}$ & $22 \cdot 9$ \\
\hline $16: 1$ & $3 \cdot 2$ & $2 \cdot 1$ & $1 \cdot 2$ & 0.7 & $3 \cdot 2$ & $1 \cdot 2^{* *}$ & 0.5 & $\operatorname{tr}$ \\
\hline 18DMA & $2 \cdot 7$ & $\operatorname{tr}$ & $\operatorname{tr}$ & $\operatorname{tr}$ & $4 \cdot 3^{*}$ & $\operatorname{tr}$ & $\operatorname{tr}$ & $\mathrm{tr}$ \\
\hline $18: 0$ & $20 \cdot 6$ & $11 \cdot 9$ & $8 \cdot 2$ & $65 \cdot 6$ & $16 \cdot 6^{* * *}$ & $16 \cdot 6^{* *}$ & $11 \cdot 7^{* * *}$ & $52 \cdot 0^{*}$ \\
\hline $18: 1 \omega 9$ & $6 \cdot 2$ & $24 \cdot 5$ & $20 \cdot 3$ & $5 \cdot 3$ & $13 \cdot 0^{* * *}$ & $26 \cdot 3$ & $26 \cdot 2^{*}$ & $8 \cdot 3^{* *}$ \\
\hline $18: 2 \omega 6$ & $1 \cdot 0$ & $2 \cdot 1$ & 0.8 & $1 \cdot 3$ & 1.0 & $2 \cdot 3$ & $1.2^{*}$ & 1.7 \\
\hline $18: 3 \omega 3$ & $0 \cdot 3$ & 0.8 & $0 \cdot 1$ & $0 \cdot 1$ & $0 \cdot 3$ & 0.8 & $0.3^{*}$ & $\operatorname{tr}$ \\
\hline $20: 0$ & $\operatorname{tr}$ & 0.1 & $\operatorname{tr}$ & $1 \cdot 3$ & 0.1 & $0 \cdot 1$ & $0 \cdot 1$ & $1 \cdot 6$ \\
\hline $20: 1$ & $0 \cdot 2$ & 0.3 & 0.3 & $0 \cdot 1$ & $0.9 * * *$ & $0.6^{*}$ & $0.6^{* *}$ & $0 \cdot 2$ \\
\hline $20: 2 \omega 6 \dagger$ & $\operatorname{tr}$ & 0.3 & $0 \cdot 1$ & $\operatorname{tr}$ & 0.1 & $0 \cdot 3$ & $0.3^{*}$ & $\mathrm{tr}$ \\
\hline $20: 3 \omega 6$ & 0.6 & 0.6 & 0.1 & $0 \cdot 1$ & 0.7 & 0.7 & $0.2^{*}$ & $\operatorname{tr}$ \\
\hline $20: 4 \omega 6$ & $9 \cdot 0$ & $5 \cdot 1$ & 0.6 & $0 \cdot 3$ & $5 \cdot 2^{* *}$ & $4 \cdot 1$ & 1.0 & $\operatorname{tr}$ \\
\hline $20: 5 \omega 3 \dagger$ & $2 \cdot 6$ & $1 \cdot 7$ & 0.1 & $0 \cdot 2$ & $1.7^{* *}$ & 1.5 & 0.1 & $0 \cdot 6^{* * *}$ \\
\hline $22: 4 \omega 3 \dagger$ & $0 \cdot 1$ & $0 \cdot 2$ & 0.1 & 0.5 & $0.8^{* * *}$ & $\operatorname{tr}$ & 0.1 & $1.9^{*}$ \\
\hline $22: 4 w 6$ & 1.9 & 0.6 & $0 \cdot 1$ & $\operatorname{tr}$ & $2 \cdot 0$ & 0.8 & 0.1 & tr \\
\hline $22: 5 \omega 6 \dagger$ & 0.4 & $0 \cdot 1$ & $\mathrm{tr}$ & $0 \cdot 3$ & $0.9 *$ & 0.2 & tr & $1 \cdot 0^{* *}$ \\
\hline $24: 1$ & $\operatorname{tr}$ & $\operatorname{tr}$ & 0.2 & $1 \cdot 2$ & $\operatorname{tr}$ & $\operatorname{tr}$ & 0.5 & $5 \cdot 7^{* * *}$ \\
\hline $22: 5 \omega 3$ & $4 \cdot 8$ & $2 \cdot 3$ & 0.1 & $0 \cdot 2$ & $7 \cdot 6^{*}$ & $3.8^{*}$ & 0.3 & $\operatorname{tr}$ \\
\hline $22: 6 \omega 3$ & $31 \cdot 4$ & $8 \cdot 4$ & $0 \cdot 4$ & $1 \cdot 2$ & $27 \cdot 0^{*}$ & $12 \cdot 4^{*}$ & $0 \cdot 7$ & $1 \cdot 1$ \\
\hline Others & $3 \cdot 6$ & 0.7 & 1.0 & 1.0 & $4 \cdot 5$ & 10.0 & 0.5 & $2 \cdot 0$ \\
\hline
\end{tabular}

Mean values for cerebellum were significantly different from those for cerebrum: ${ }^{*} P<0.05,{ }^{* *} P<0.01$. $* * * \mathrm{P}<0.001$

tr, trace $(<0 \cdot 1 \%)$; DMA, dimethyl acetal.

$\dagger 20: 2 \omega 6,20: 5 \omega 3,22: 4 \omega 3$ and $22: 5 \omega 6$ contain traces of $21: 0,22: 1,22: 0$ and $24: 0$ respectively. 
Values for the FA composition of lipid fractions obtained from three chicks given diet $\mathrm{L}$ are presented in Table 4. Additional values from two diet-S-fed chicks (not shown) were generally similar, except for the higher $\omega 6$-FA and lower $\omega 3$-FA values. The values in Table 4 bring out differences between cerebrum and cerebellum not revealed by analysis of total FA: stearic acid in EPG and SPH was higher in the cerebrum, while its concentration in SPG and CPG was higher in the cerebellum. Also, the cerebellar level of oleic acid exceeded that in the cerebrum in all fractions except SPG, and palmitic acid in the SPG and CPG fractions was higher in cerebrum than in cerebellum. Other differences among the major

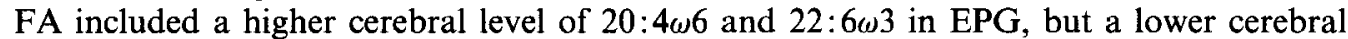
value for 22:5 33 in EPG and SPG. The nervonic acid (24:1) content of SPH was markedly higher in the cerebellum than in the cerebrum.

The FA composition of the cerebrum differed from that of the cerebellum in several respects. The latter were richer in unsaturated FA and poorer in saturated FA than the former. The double-bond index (average number of double bonds per FA), calculated from the analytical results at 4 weeks, was 1.74 in the cerebrum $v .1 .85$ in the cerebellum with diet $\mathrm{S}$, while the corresponding values for the diet $\mathrm{L}$ group were 1.89 v. $2.05(P<0.01$ for cerebrum $v$. cerebellum in both dietary treatments, and $P<0.01$ for diet S $v$. diet $\mathrm{L}$ in both parts of the brain).

\section{DISCUSSION}

The present results relate to two aspects of brain FA composition in the young chick, namely (1) the difference between cerebrum and cerebellum and (2) the effect of a dietary supply of LnA from linseed oil $v$. LA from safflower oil.

\section{Cerebrum v. cerebellum}

The greater unsaturation of the cerebellar FA seems to be the result of two factors: (1) the higher PUFA values in the cerebellum, due in turn to the elevated EPG content (Table 3), EPG being by far the richest source of long-chain PUFA among the brain lipids examined (Table 4); and (2) the higher cerebellar concentrations of oleic acid in EPG, CPG and SPH, and of nervonic acid (24:1) in SPH, compared with the corresponding values in the cerebrum (Table 4).

The reversal of the relative proportions of stearic and oleic acids between cerebrum and cerebellum (Table 2) can be accounted for, in part, by the higher cerebellar EPG content and by the concentrations of stearic and oleic acids in the various lipids in the two parts of the brain. Surprisingly, the weight $\%$ of total FA as $\mathrm{C}_{18} \mathrm{FA}$ was the same in cerebrum and cerebellum (34.7 and $34.4 \%$ respectively with diet $S$, and 36.6 and $37.0 \%$ with diet $\mathrm{L}$ ). According to preliminary findings from this laboratory, the ratio, stearic: oleic acid is lower in the cerebellum than in the cerebrum also in mammalian species such as rat, guinea-pig and rabbit, while total $\mathrm{C}_{18} \mathrm{FA}$ levels are very similar in the two brain regions.

Another distinguishing feature that sets the cerebellum apart from the cerebral hemispheres is the kinetics of PUFA acquisition during the experimental period, as shown in Fig. 2. Recalculation of the values in terms of mg PUFA per cerebrum or cerebellum reveals an accelerated rate of PUFA accretion between days 11 and 21 in the cerebellum but not in the cerebrum. This cerebellar spurt in PUFA accretion was observed not only for total PUFA, total $\omega 6$-PUFA and total $\omega 3$-PUFA, but also in the case of $20: 4 \omega 6$ with diet $\mathrm{S}$ and 22:6 33 with diet $\mathrm{L}$. The cerebellar PUFA spurt was far more pronounced than the increased rate of accretion of total FA shown in Fig. 1.

$$
L A \text { v. } \operatorname{Ln} A
$$

The dietary oils used in the present study represent the extremes of LA and LnA contents 
and induce corresponding changes in the levels of $\omega 6$ - and $\omega 3$-PUFA in the brain (Table 2, Fig. 2). This effect largely reflects the availability of $\omega 6$ - and $\omega 3$-acyl groups for incorporation into brain lipids, as determined by the dietary supply levels of the precursor $\mathrm{FA}$, and the conversion efficiency to the desaturation-elongation products. The conversion itself is greatly affected by the mutual inhibitory effects of the precursor FA, as illustrated by the strong inhibition by LnA of the conversion of LA to AA in liver in vivo (Mohrhauer \& Holman, 1963). Furthermore, there is a high degree of selectivity in the incorporation of individual FA into brain lipids: this is clearly illustrated by the fact that in the diet-L-fed chicks, the liver manufactures $20: 5 \omega 3$ as the major $\omega 3$ conversion product (Budowski et al. 1980), whereas in brain, there is a roughly tenfold excess of $22: 6 \omega 3$ over $20: 5 \omega 3$ (Table 2 ).

The relatively slight effect of the dietary treatments on the total PUFA contents of cerebral and cerebellar FA indicates that the chick is capable of close regulation of its total brain PUFA content, irrespective of the dietary regimen and the predominance of either $\omega 6-$ or $\omega 3-\mathrm{FA}$ in its brain. Such a control has also been observed repeatedly in rat brain, most recently by Nouvelot et al. $(1983 a, b)$.

The effects of the dietary oils on the oleic acid content of brain FA was unexpected. The safflower and linseed oils contained similar weight \% of total FA of oleic acid (15.9 and $15.5 \%$ respectively) and had only 2.3 and $3.0 \%$ stearic acid, so that the oil effect cannot have been caused by differences in the dietary supply of these two FA. Retrospective examination of findings collected in a previous study with diets deficient in vitamin $\mathrm{E}$ and containing $8 \%$ methyl esters prepared from safflower and linseed oils (Budowski et al. 1980 ) revealed a similar effect on the oleic acid content of liver EPG : $2 \cdot 10 \%$ with diet $S$ (n 11) and $2.85 \%$ with diet $\mathrm{L}(n 14, P<0.25)$. This suggests that LnA enhances the hepatic biosynthesis of oleic acid, compared with the effect of LA.

\section{$A$ new interpretation of the etiology of $N E$}

Some of the present findings may help in understanding several aspects of chick NE. Thus, the fact that the cerebellum constitutes the target organ, while the cerebrum is not affected, may be related to the dramatic increase in PUFA levels that was observed between days 11 and 21 in the cerebellum, but not in the cerebrum. We have repeatedly observed that, with vitamin-E-deficient diets and under conditions otherwise similar to those of the present experiment, symptoms of NE begin to appear about day 12, reach maximum frequency about day 16 and become increasingly rare after the end of the 3 rd week. A similar picture of NE incidence was described by Marco et al. (1961), who, however, reported an increase in LA + AA content in the cerebellar lipids between days 7 and 11 , before the incidence of symptoms became maximal. This increase is earlier than ours but could be due to differences in diets, breed of chicks or possibly also to differences in techniques: in the present study, the FA analyses included the $\mathrm{C}_{22}$ chain-length PUFA and sampling was done at more frequent intervals.

Fig. 3 represents an attempt at depicting the mechanism of induction of NE by LA and the protecting effect of LnA. It is a modified version of a scheme put forth previously (Budowski et al. 1980). The central feature in the development of the lesion is the overproduction of eicosanoids brought about by the lack of $\alpha$-tocopherol and the resulting increase in peroxide tone (Warso \& Lands, 1983). The initiating event is the formation of ischaemic foci (Dror et al. 1976) as the result of thrombus formation in the microvessels of the cerebellum (Budowski et al. 1980). Chick aorta produces prostaglandin $\mathrm{E}_{2}\left(\mathrm{PGE}_{2}\right)$, rather than prostacyclin $\left(\mathrm{PGI}_{2}\right)$ (Subbiah et al. 1980; Claeys et al. 1981) which would also affect thrombogenesis. Tissue damage can then spread rapidly via phospholipase $\mathrm{A}_{2}$ (EC 3.1.1.4) activation and further eicosanoid production from membrane arachidonate. On the other hand, LnA interferes with different steps in the previously described chain of 


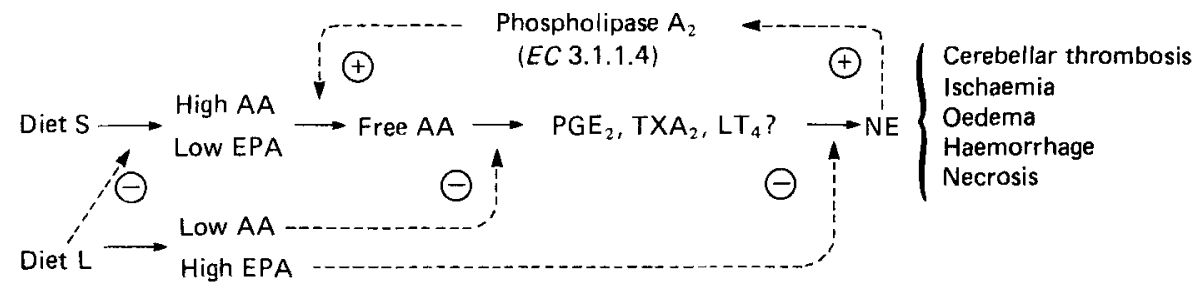

Fig. 3. Tentative scheme describing the induction of nutritional encephalomalacia (NE) in the vitaminE-deficient chick by linoleic acid (safflower (S) diet) and the protective effect of $\alpha$-linolenic acid (linseed (L) diet). +, Activation; - , inhibition; AA, arachidonic acid; EPA, eicosapentaenoic acid; PGE $_{2}$, prostaglandin $\mathrm{E}_{2} ; \mathrm{TXA}_{2}$, thromboxane $2 ; \mathrm{LT}_{4}$, leukotriene 4 .

events. The biosynthesis of AA and its conversion to prostanoids and leukotrienes are inhibited by LnA and its long-chain metabolites; and it is possible that $\omega 3-\mathrm{FA}$ also attenuate the damaging action of AA-derived eicosanoids on the cerebellum, since an increased peroxide tone favours the production of 20:5 23 -derived prostanoids (Warso \& Lands, 1983).

In a study of thirty-two different species, the balance of the $\omega 6$ - and $\omega 3-\mathrm{FA}$ in the brain approximated $1: 1$ throughout and it has been proposed that this balance is appropriate for optimum structural considerations (Crawford et al. 1976). Furthermore, the profile of the individual FA was similar regardless of species or their adaptation to different food structures. The chick brain, unlike the brain of other species, appears to be very responsive to changes in dietary fats, which may be related to the rapid weight gain of the young chick. Dobbing (1972) has suggested that the vulnerable period for the brain is during its growth phase, thereafter it is carefully protected. Our FA findings suggest that in the chick a rapid developmental phase occurs in the cerebellum but not the cerebrum during the period when the susceptibility to NE is at its maximum. Continued exposure to a high-LA, low-vitamin$\mathrm{E}$ diet beyond that period is not usually accompanied by an increased incidence of $\mathrm{NE}$. Therefore it seems that it is this developmental phase in the cerebellum which makes it sensitive, unlike the cerebrum. To borrow Dobbing's (1972) phrase: days 11 to 21 appear to be a 'vulnerable period' for the cerebellum in the chick.

The distortion of the balance of FA in the cerebellum under the influence of a diet low in $\omega 3-\mathrm{FA}$ and high in $\omega 6-\mathrm{FA}$ is very far from that usually encountered in brain structural lipid. A collapse of endothelial and cellular integrity in response to demand outstripping the supply of $\omega 3-\mathrm{FA}$ would predictably lead to haemorrage, phospholipase $\mathrm{A}_{2}$ release, exposure of thrombocytes to collagen and excessive eicosanoid production. The anticipated response to initial injury could result in cataclysmic events consistent with death rapidly following the first signs of ataxia.

\section{REFERENCES}

Budowski, P., Bartov, I., Dror, Y. \& Frankel, E. N. (1979). Lipids 14, 768-780.

Budowski, P., Hawkey, C. M. \& Crawford, M. A. (1980). Annales de la Nutrition et de I Alimentation 34, $389-400$

Century, B. \& Horwitt, M. K. (1959). Proceedings of the Society for Experimental Biology and Medicine 102, 375-377.

Century, B., Horwitt, M. K. \& Bailey, P. (1959). American Medical Association's Archives of General Psychiatry 1, 420-424.

Century, B., Witting, L. A., Harvey, C. C. \& Horwitt, M. K. (1963). American Journal of Clinical Nutrition 13, 362-368.

Claeys, M., Wechsung, E., Herman, A. G. \& Nugteren, D. H. (1981). Prostaglandins 21, 739-749.

Crawford, M. A., Casperd, N. M. \& Sinclair, A. J. (1976). Comparative Biochemistry and Physiology 54b, 395-401. 
Dam, H., Nielsen, G. K., Prange, I. \& Sondergaard, E. (1958). Nature 182, 802-803.

Dam, H. \& Sondergaard, E. (1962). Zeitschrift für Ernaehrungswissenschaft 2, 217-222.

Dobbing, J. (1972). In Lipids, Malnutrition and the Developing Brain, Ciba Foundation Symposium, pp. 9-20 [K. Elliott and J. Knight, editors]. Amsterdam: Elsevier.

Dror, Y., Budowski, P., Bubis, J. J., Sandbank, U. \& Wolman, M. (1976). In Progress in Neuropathology, vol. 3, pp. $343-357$ [H. M. Zimmerman, editor]. New York: Grune \& Stratton.

Horwitt, M. K., Harvey, C. C. \& Century, B. (1959). Science 130, $917-918$.

Machlin, L. J. \& Gordon, R. S. (1960). Proceedings of the Society for Experimental Biology and Medicine 103, 659-663.

Marco, G. J., Machlin, L. J., Emery, E. \& Gordon, R. S. (1961). Archives of Biochemistry and Biophysics 94, 115-120.

Mohrhauer, H. \& Holman, R. T. (1963). Journal of Lipid Research 4, 151-159.

Neuringer, M., Connor, W. E., Lin, D. E., Barstad, L. \& Luck, S. (1986). Proceedings of the National Academy of Science, USA 83, 4021-4025.

Nouvelot, A., Bourre, J. M., Sezille, G., Dewailly, P. \& Jaillard, J. (1983a). Annals of Nutrition and Metabolism 27, 173-181.

Nouvelot, A., Dedonder-Decoopman, E., Sezille, G., Paturneau-Jouas, M., Dumont, O., Masson, M. \& Bourre, J. M. (1983b). Annals of Nutrition and Metabolism 27, 233-240.

Pappenheimer, A. M. \& Goettsch, M. (1931). Journal of Experimental Medicine 53, 11-26.

Sinclair, A. J. \& Crawford, M. A. (1973). British Journal of Nutrition 29, 127-137.

Sinnhuber, R. O., Castell, J. D. \& Lee, D. J. (1972). Federation Proceedings 31, 1436-1441.

Subbiah, M. T. R., Deitemeyer, D. \& Yunker, R. (1980). Thrombosis and Haemostasis (Stuttgart) 43, $189-191$.

Tinoco, J., Babcock, R., Hincenbergs, I., Medwadowski, B. \& Miljanich, P. (1978). Lipids 13, 6-17.

Vitiello, F. \& Zanetta, J.-P. (1978). Journal of Chromatography 166, 637-640.

Warso, M. A. \& Lands, W. E. M. (1983). British Medical Bulletin 39, 277-280. 